\title{
Clinical Management of Locally Advanced Basal-Cell Carcinomas and Future Therapeutic Directions
}

Dennis Niebel (D) · Judith Sirokay · Friederike Hoffmann •

Anne Fröhlich · Thomas Bieber · Jennifer Landsberg

Received: April 2, 2020 / Published online: May 7, 2020

(C) The Author(s) 2020

\section{ABSTRACT}

Treatment of choice for nodular basal-cell carcinomas (BCCs) is complete excision, implying that small lesions are of minor concern. Metastasis is very rare $(<1 \%)$. However, locally advanced basal-cell carcinomas (laBCCs), which are ineligible for surgery or radiation, are a therapeutic challenge. First-generation Smoothened (SMO) inhibitors (vismodegib, sonidegib) have been approved for treatment, but common side effects limit their use. Numerous new compounds are being investigated in clinical trials as potential therapeutic alternatives, among them secondgeneration SMO inhibitors, other Hedgehog signaling pathway inhibitors, immune-checkpoint inhibitors and intralesional modalities such as oncolytic viruses. Neoadjuvant treatment regimens open another field. This article deals with the clinical management of laBCCs, based on the description of an illustrative case from our department featuring multiple extensive lesions of the scalp. In this short review we will discuss therapeutic options and implications for the future. Some of the new strategies might

Digital Features To view digital features for this article go to https://doi.org/10.6084/m9.figshare.12180051.

D. Niebel $(\varangle) \cdot$ J. Sirokay · F. Hoffmann .

A. Fröhlich · T. Bieber · J. Landsberg

Clinic for Dermatology and Allergy, University

Hospital Bonn, 53127 Bonn, Germany

e-mail: Dennis.Niebel@ukbonn.de potentially evolve as alternatives in the management of genodermatoses such as basal-cell carcinoma syndrome, if proven effective and safe.

Keywords: Basal-cell carcinoma; Basal-cell carcinoma syndrome; Immunotherapy; Radiotherapy; Rodent ulcer; Smoothened receptor

\section{Key Summary Points}

Basal-cell carcinoma is the most common malignant cutaneous tumor.

Generally, margin-controlled complete excision is the first line treatment option for nodular lesions.

This case report is an illustrative example of challenges encountered in clinical practice as locally advanced tumors ineligible for surgery require a tailored interdisciplinary approach.

Potential therapeutic modalities include radiotherapy, targeted therapy (Hedgehog signaling inhibitors), immune oncology, electrochemotherapy and oncolytic virotherapy.

Basal-cell carcinoma syndrome patients might benefit from well-tolerable medical therapies to avoid repetitive surgery. 


\section{INTRODUCTION}

\section{Epidemiology and Pathogenesis}

Millions of patients in the USA are diagnosed with skin cancer yearly, among which basal-cell carcinoma (BCC) is the most frequent [1]. The ever-rising incidence over the last decades has been recognized as a result of demographic transition and high exposition to ultraviolet (UV) radiation among large parts of the population. The economic burden in the USA is substantial, as treatment costs for non-melanoma skin cancers (NMSCs) add up to about 5 billion US dollars annually [2]. Although metastasis is very rare, an estimated 3000 patients die from BCCs in the USA yearly [3].

Like other NMSCs, BCCs usually affect patients of Fitzpatrick skin phototypes I-II. Register data suggest androtropism (male:female ratio 2:1). Predilected areas are the head and neck followed by the arms, legs and trunk. Apart from excessive UV exposure and genetic conditions, pathogenetic factors include immunosuppression, exposure to chemicals (e.g., arsenic) and ionizing radiation. Overactivation of the Sonic Hedgehog (HH) signaling pathway is the causative driver of disease as an inactivating mutation of patched (PTCH) proteins causes $90 \%$ of sporadic BCCs. Activating Smoothened (SMO) protein mutations account for another relevant proportion of tumors. PTCH1 physiologically inhibits SMO; the aberrant loss of this function ultimately leads to interference with apoptosis and uncontrolled growth of tumor cells. This mechanism was first identified in patients suffering from basal-cell carcinoma syndrome (BCCS), which paved the way for the development of specific inhibitors. Numerous further cancer-associated genes have been found to frequently carry UV-induced mutations in BCCs that might be of therapeutic relevance in the future $[4,5]$.

\section{Clinical}

BCCs are heterogeneous tumors that are clinically divided into nodular, superficial, sclerosing, pigmented, ulcerative and destructive types, among which the ulceronodular type is the most frequent. Usually these tumors are detected by clinical inspection. They present as skin-colored or erythematous papules and plaques with slightly elevated margins and prominent vessels (teleangiectasia); ulceration is common. Dermatoscopy and other noninvasive techniques such as optical coherence tomography or confocal laser microscopy may further improve diagnostic accuracy [4]. Numerous histologic subtypes have been described among which specific ones bear a higher risk of recurrence or an unfavorable course (e.g., basosquamous BCC). Nonetheless, anatomic location is very important as the central face has been identified as a high risk area for recurrences. Peris et al. proposed a new practical approach to distinguish between "easy to treat" and "difficult to treat" BCCs [5]. This classification depends on clinical aspects such as technical or aesthetical difficulties due to the size of the lesion and anatomic region, poorly defined borders and infiltrative growth, prior recurrences or prior radiotherapy and patient characteristics (e.g., comorbidity). The term locally advanced basal-cell carcinoma (laBCC) was used in clinical trials and is vaguely defined; it comprises a group of tumors that can be considered "difficult to treat" BCCs in any circumstance as they require an interdisciplinary approach. Hallmark characteristics include involvement of vitally or functionally important structures (e.g., intracranial extension, periocular region) and impossibility to definitely achieve complete resection. Of note, the TNM staging system of malignant tumors is unsuitable to accurately classify BCCs as it does not reflect these parameters and both regional and distant metastases seldom occur.

BCCS (synonyms: nevoid basal-cell carcinoma syndrome, Gorlin syndrome, basal-cell nevus syndrome) is a rare genetic disorder characterized by the development of multiple BCCs at a young age in the presence of other congenital abnormalities [6]. Affected patients require repetitive surgery over time, which severely impacts quality of life. Other relevant genodermatoses predisposing to the development of BCCs in young patients are xeroderma 
pigmentosum (XP), albinism, Rombo syndrome and Bazex-Dupré-Christol syndrome.

\section{Therapeutic Options}

Early detection of tumors is important to enable uncomplicated treatments. Small or superficial lesions, especially of the trunk, may be handled with cryotherapy, photodynamic therapy, electrodesiccation and curettage, topical immunomodulators (imiquimod) or topical chemotherapy (5-fluoruracil) if the patient is reliably compliant to clinical follow-up [7]. If available, Mohs surgery or micrographic margin-controlled excision is preferred for high-risk BCCs to reduce the risk of local recurrences [8]. "Difficult to treat" BCCs comprise about 5\%, and laBCCs account for about $0.8 \%$ of all BCCs [5]. Depending on the tumor site, ophtalmologists, otorhinolaryngologists and plastic and reconstructive surgeons should be involved in the pretherapeutic scheduling of imaging studies and assessment of operative procedures $[9,10]$. Upon excision, even large defects in sensitive areas may be reconstructed by experts using sophisticated techniques [11]. However, BCCs are typically tumors with high radiosensitivity. Therefore, radiation may be an alternative if curative surgery is predictably associated with severe morbidity (e.g., mutilating or disfiguring procedures) $[8,12]$. Disadvantages include the lack of histopathologic examination, dose limitations and the risk of secondary tumors. Systemic treatment should be considered if both surgery and radiation fail to achieve disease control. To illustrate challenges in the management of laBCCs, we here describe the extraordinary clinical course of a female patient from our clinic. We address drawbacks to the use of SMO inhibitors and discuss potential future therapeutic directions. The patient has consented to the submission of the case report to the journal and signed informed consent regarding publishing her data and photographs.

\section{CASE REPORT}

\section{History}

A 67-year old female Caucasian patient first visited our department in November 2010. She remembered having over 50 operations for BCCs on her head in the past, the first dating back around 40 years. Apart from surgery, she had received radiotherapy of the scalp in the former Soviet Union around 30 years ago; however, the mode, dose, duration and number of treatments were not known because of missing documentation. The patient did not regularly seek medical advice and did not participate in screening programs. Respectively, she did not take any medication on a regular basis, especially no UV-sensitizing drugs. There was no family history of NMSC; she had not been exposed to noxious agents such as arsenic or tar. Neither relevant comorbidity nor immunosuppression was present, and she had not experienced occupational sun exposure. The patient had no history of brain tumors or skeletal abnormalities (e.g., cysts).

\section{Clinical Picture}

The patient displayed numerous large ulcerated tumors on the scalp, partly arising in the area of a former skin graft on her right forehead (Fig. 1). An early lesion showed the typical appearance of BCC displaying multiple skin-colored nodules arranged as beads with aberrant vascularization on her right neck (Fig. 2). There were no signs of chronic actinic damage such as cutis rhomboidalis nuchae, poikiloderma or FavreRacouchot syndrome; there were no actinic keratoses. Full-body examination revealed no signs of palmoplantar pits or other skin abnormalities. A cranial computer tomography exposed minimal calcification of the cerebral falx; further investigations revealed no skeletal cysts or cardiac fibromas. The frontoparietal circumference was normal. 


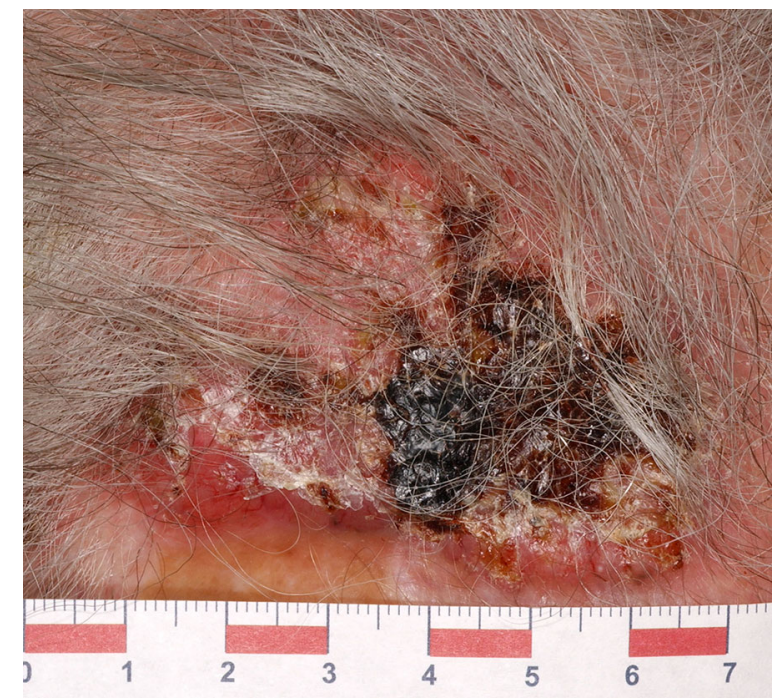

Fig. 1 Clinical findings upon first presentation in 2010: large ulcerated basal-cell carcinomas in the right frontal and parietal area. A tumor relapse was suspected as a prior skin graft on her forehead was affected

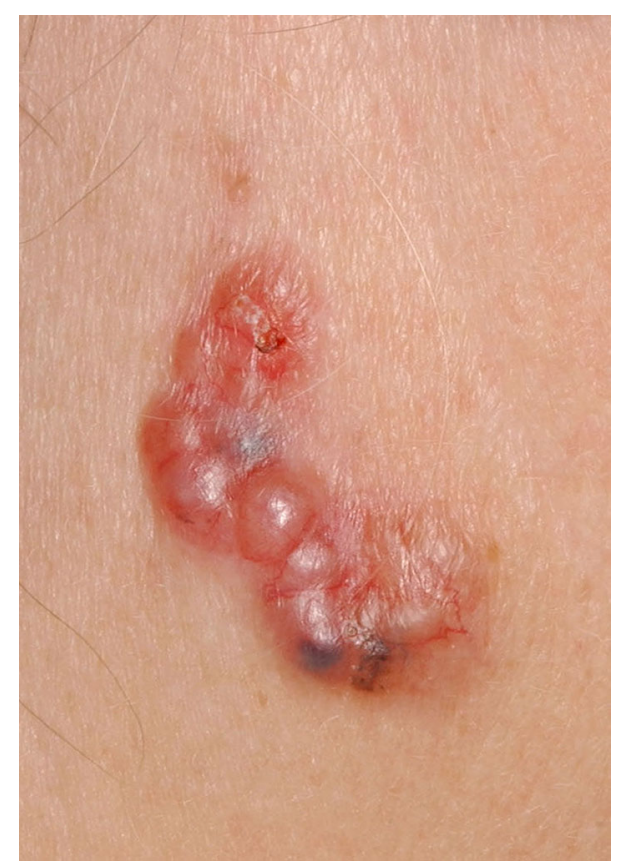

Fig. 2 Clinical findings upon first presentation in 2010: an earlier tumor in the right retroauricular area showed the typical appearance of BCC with multiple skin-colored nodules arranged as beads with aberrant vascularization

\section{Laboratory Investigations}

There was no evidence of renal or hepatic organ dysfunction; a complete blood count revealed no pathologies apart from hypochromic anemia $(11.1 \mathrm{~g} / \mathrm{dl}$, reference range $11.8-15.8 \mathrm{~g} / \mathrm{dl})$.

\section{Diagnosis}

- Multiple "difficult to treat" BCCs of the scalp.

- BCCS suspected clinically.

\section{Clinical Course}

The patient agreed to an extensive histographically controlled excision of the frontal tumor. Upon confirmation of tumor-free margins, a split-skin graft was used for defect closure and the patient was discharged from the clinic. Further excisions were scheduled, including the tumor of the right neck, but the patient did not keep her appointments. Instead, she only returned to the clinic 9 years later in May 2019. The pre-existing tumors and new lesions had grown dramatically over the course of time; the patient experienced recurrent bleeding and was ashamed to leave the house (Fig. 3). The lesion of her right neck was now well pedunculated and partly fibrotic at the base (Fig. 4). It could easily be excised, along with BCCs of the upper lip and eyebrow (not shown). The massive tumors on her scalp required extensive and mutilating surgery, which the patient refused. She fulfilled two major diagnostic criteria of BCCS: diagnosis of a BCC at age $<30$ years and abnormal calcification of the falx cerebri. All other clinical criteria were negative, including family history. We also considered other genodermatoses such as XP. These patients lack sufficient deoxyribonucleic acid repair capacity and are prone to development of ultraviolet light-induced skin cancer; certain groups of patients tend to develop NMSC in the 3rd decade of life (e.g., XP variants $\mathrm{E} / \mathrm{V}$ ). However, other features of XP were absent in this patient (freckling, cataract), and the condition is very rare in Europe. Unfortunately, the patient 

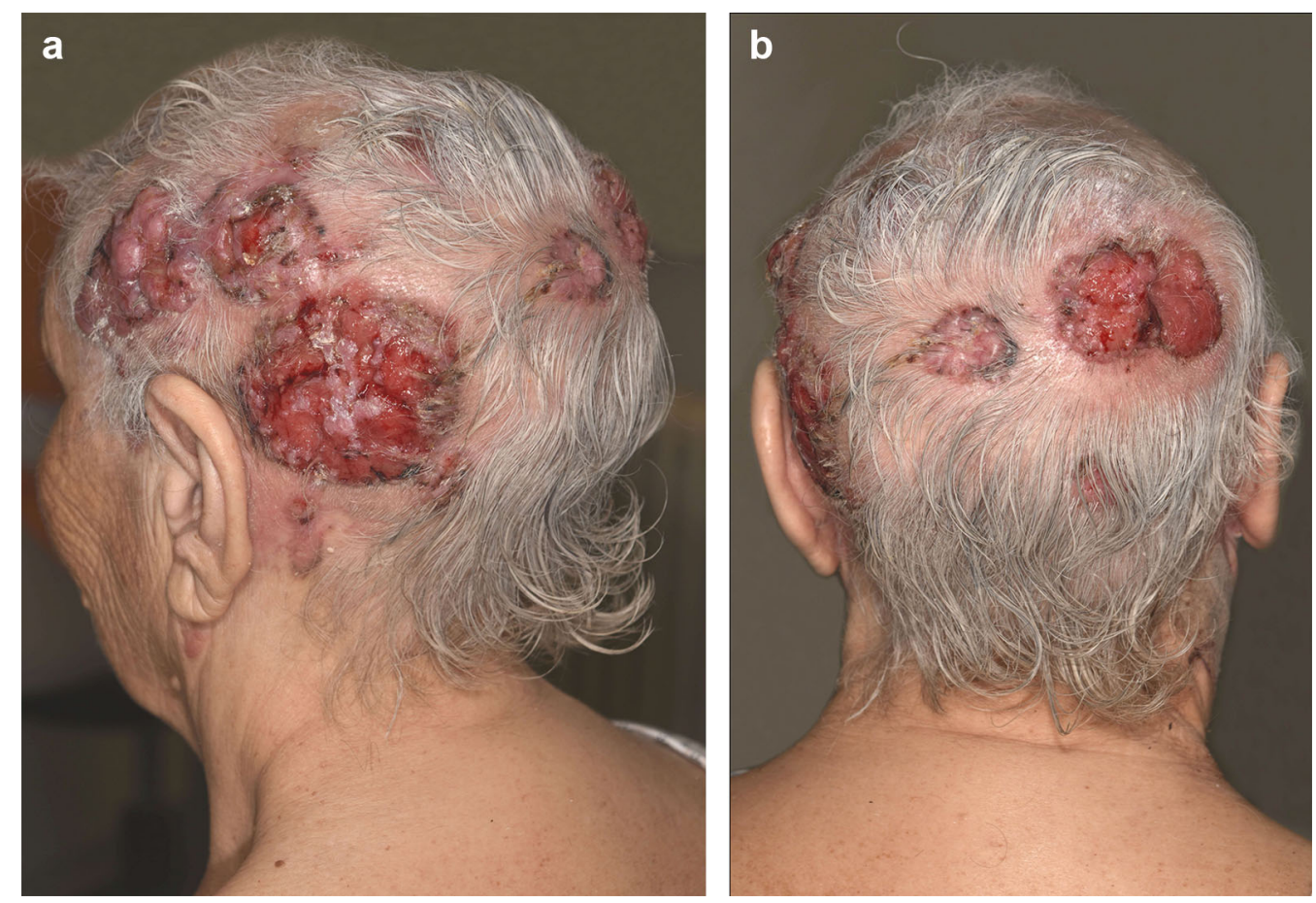

Fig. 3 Clinical findings upon second presentation in 2019: extensive ulcerated basal-cell carcinomas dispersed on the scalp most severely involving the left temporal and occipital area

refused to undergo a further human genetic diagnostic evaluation for possible abnormalities. Still, given the possibility of a genodermatosis, we excluded further radiation because of the risk of potentially provoking new BCCs. In the absence of contraindications, we initiated treatment with vismodegib in standard dosing (150 mg daily), which had to be withdrawn after 1 month because of severe muscle spasms. Even though the creatine kinase level was normal, neither an off-label dose reduction every other day nor magnesium intake improved the cramps. We switched treatment to sonidegib in standard dosing (200 mg daily), which was initially better tolerated. However, the patient decided to terminate treatment 2 months later, as she planned a trip and still felt impaired by intermittent muscle spasms. However, we were able to achieve a fascinating partial remission after only 3 months of treatment (Fig. 5). After drug dismissal, the patient did not report to our center again, despite repeated calls and written invitations.

\section{DISCUSSION}

The clinical course of the patient clearly shows the difficulties in the management of BCCs in non-compliant patients. Based on the natural progression of disease, this case report is suitable for further reflection on treatment options for laBCCs. Numerous new compounds are being investigated in clinical trials as potential therapeutic alternatives including new $\mathrm{HH}$ signaling pathway inhibitors, immune-checkpoint inhibitors and intralesional modalities (Table 1). For "difficult to treat" BCCs that cannot be treated with complete excision because of the size, site, age and comorbidity of the patient, the indication for the following treatment modalities should be considered in an interdisciplinary approach (tumor board) $[5,9]$.

\section{Radiotherapy}

Based on high radiosensitivity of BCCs, radiotherapy is a viable and generally well-tolerated 


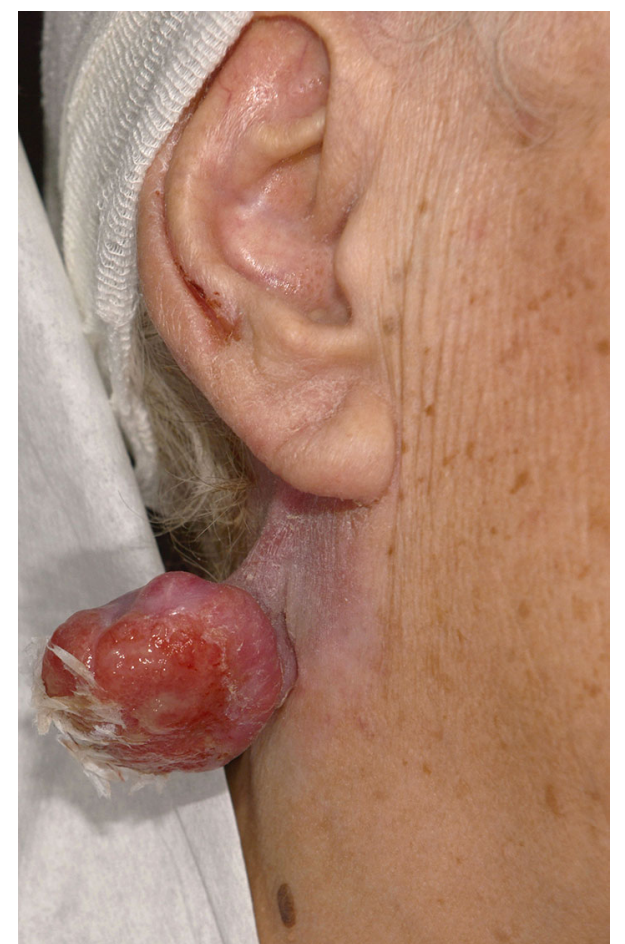

Fig. 4 Clinical findings upon second presentation in 2019: the tumor in the right retroauricular area had grown extensively in an unusual pedunculated manner leading to fibrosis of the base

option for singular extensive lesions. Common modalities with similar efficacy include interstitial brachytherapy, contact therapy and conventional fractionated radiotherapy [13]. Radiation therapy should also be considered for adjuvant treatment of high-risk BCCs with perineural involvement and if tumor-free margins are not reached by surgery of justifiable extent [8]. It remains a hallmark therapy option, especially in elderly patients with a limited life expectancy who require reliable disease control. BCCS patients may have soaring numbers of tumors following radiotherapy and ionizing radiation because of accumulation of new mutations. Therefore, it should be avoided in these patients, although some authors consider it safe at least for adult patients [14]. Other contraindications include connective tissue diseases (e.g., lupus erythematosus) as they carry an increased risk of acute toxicity [9]. Radiation of tumors close to radiosensitive organs (e.g., eye, internal ear) may evoke permanent damage and must be well considered.

\section{HH Signaling Pathway}

Almost all BCCs have mutations in the $\mathrm{HH}$ signaling pathway, which were first described in BCCS. Key players are SMO, a seven-membrane spanning receptor constantly overactivated by $\mathrm{PTCH}$ protein in the presence of $\mathrm{HH}$, and the downstream effectors of the Gli family, which accumulate in the nucleus to promote cell growth [15]. The first-in-class specific SMO inhibitor vismodegib showed high clinical efficacy in both laBCC and metastatic BCC, which gave rise to the approval for both indications in the US and Europe [16, 17]. It is now considered a first-line option for tumors refractory to or not eligible for surgery and radiotherapy. Another equally effective, commercially available, approved SMO inhibitor is sonidegib [18]. Both drugs have a similar mechanism of action: thus, upon resistance, it is usually not beneficial to use one in place of the other. Another major drawback of both agents is a characteristic adverse event profile including dysgeusia, muscle spasms, weight loss, asthenia and alopecia, affecting the majority of patients [19]. Side effects are usually not life threatening, but therapy limiting in up to a third of cases as they greatly affect quality of life. Different intermittent treatment regimens are being explored as alternatives to continuous treatment, especially for BCCS patients [20]. Still, many patients ask to discontinue treatment as they consider the side effects unbearable, even in the face of visible remissions. Primary or secondary resistance is another clinical challenge, as spontaneous SMO mutations and selection of preexisting SMO-mutated clones occur during therapy and $\mathrm{HH}$ signaling may be overactivated downstream of SMO [21]. HH signaling is crucial for organogenesis; hence, both drugs are teratogenic, and strict contraceptive measures are obligatory for female patients (combination of two contraceptive methods) and male patients (condom use) during treatment. Contraindications to vismodegib and sonidegib use include pregnancy, breastfeeding and intolerance to the 

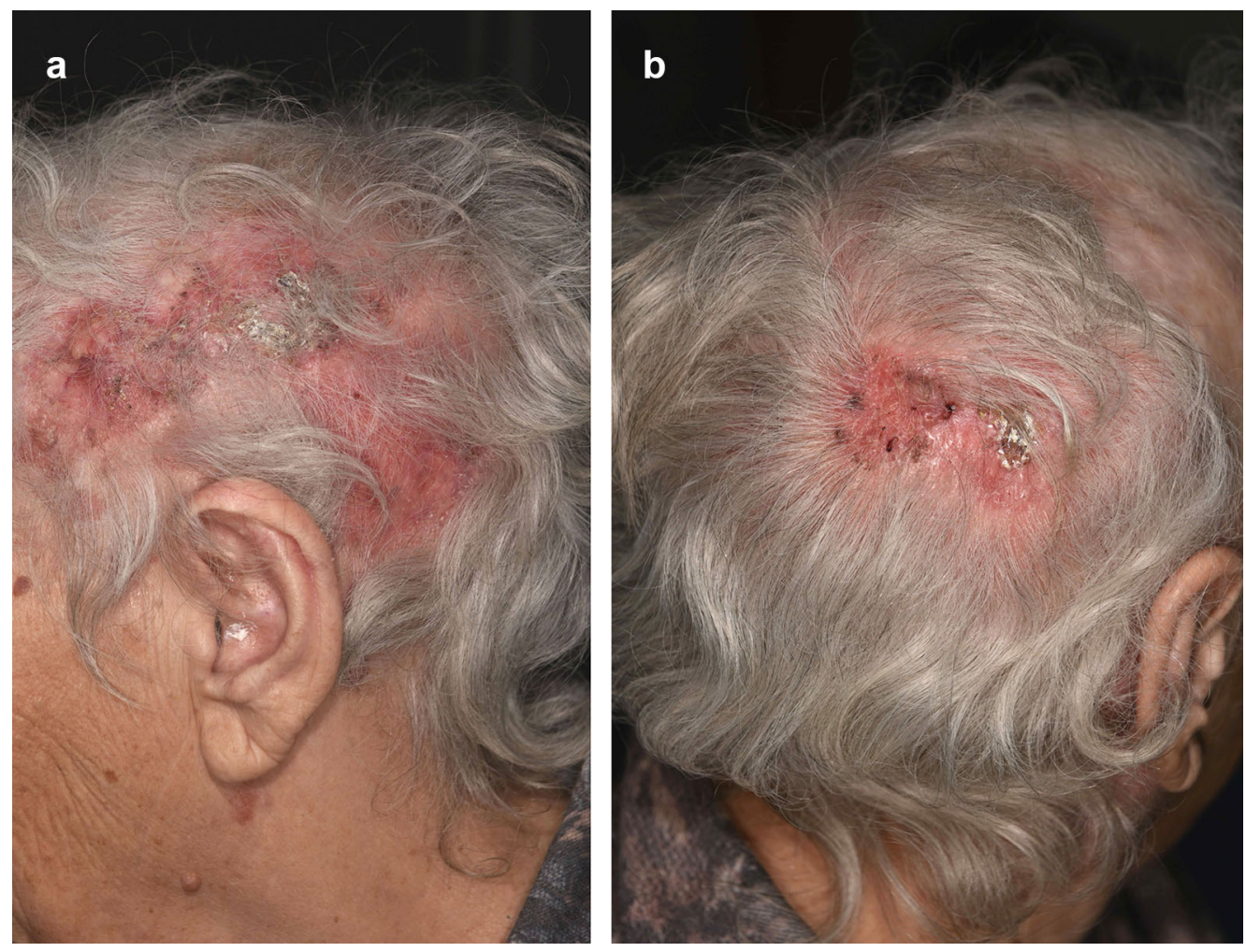

Fig. 5 Clinical findings upon targeted therapy with SMO inhibitors for 3 months: impressive partial remission of all tumors

drugs. On the other hand, renal and hepatic organ dysfunction is no criterion for exclusion; regular laboratory controls are advisable.

Many other molecules show inhibitory effects on $\mathrm{HH}$ signaling, e.g., the antimycotic agent itraconazole [15]. Therefore, it could be a favorable, cost-effective alternative with fewer side effects and additional anti-cancerous activity such as antiangiogenic effects. Liver damage, congestive heart failure and drug interactions are major concerns related to longterm itraconazole treatment. Clinical studies evaluate both topical [22] and systemic administration [23] with partly discouraging results for the former. Posaconazol, as a second-generation triazole, has not yet entered clinical trials but showed inhibitory activity on $\mathrm{HH}$ signaling in vitro [24]. Arsenic trioxide, which is commonly used to treat acute promyelocytic leukemia, is another agent of interest. As a Gli1 inhibitor, it is in early clinical investigation in combination with itraconazole (NCT02699723). Topical use of specific SMO inhibitors is an attractive approach to avoid adverse events. Patidegib (saridegib, IPI-926) as a $2 \%$ or $4 \%$ gel formulation has shown the potential to shrink facial BCCs in BCCS patients and will be further evaluated in a phase 3 trial [25]. Along with other second-generation SMO inhibitors (e.g., taladegib, LEQ-506, BMS833923, TAK-44, ZSP1602), patidegib has also entered early clinical trials for systemic treatment of advanced BCCs [24]. Safety and efficacy remain to be verified. So far, no larger studies have been launched. Apart from drug safety, whether primary and secondary resistance to vismodegib and sonidegib can be overcome with new agents will be pivotal. It is noteworthy that re-challenging with the same drug may show efficacy after initial disease progression [24]. Casein kinase 2 affects the terminal components of the signaling cascade; therefore, inhibition might be less susceptible to acquired resistance. Currently, a phase 1 study determines the pharmacodynamic profile of silmitasertib (NCT03897036). 
Table 1 Overview of medical therapeutic modalities for locally advanced and metastatic basal-cell carcinomas and selected clinical studies

\begin{tabular}{|c|c|c|c|c|c|c|}
\hline $\begin{array}{l}\text { Mode of } \\
\text { action }\end{array}$ & Class & Drug & Dosage & Setting & $\begin{array}{l}\text { FDA } \\
\text { approval }\end{array}$ & $\begin{array}{l}\text { EMA } \\
\text { approval }\end{array}$ \\
\hline \multirow{11}{*}{$\begin{array}{l}\text { Hedgehog } \\
\text { signaling } \\
\text { inhibitors }\end{array}$} & \multirow{10}{*}{$\begin{array}{l}\text { SMO } \\
\text { inhibitors }\end{array}$} & Vismodegib & $150 \mathrm{mg} \mathrm{1x/d} \mathrm{p.o}$ & $\mathrm{laBCC} / \mathrm{mBCC}$ & $01 / 2012$ & $07 / 2013$ \\
\hline & & Sonidegib & $200 \mathrm{mg} \mathrm{1x/d} \mathrm{p.o}$ & laBCC & $07 / 2015$ & $08 / 2015$ \\
\hline & & Itraconazole & $\begin{array}{l}\text { Pilot Biomarker Trial: } \\
\text { 100-200 mg 2x/d p.o. } \\
\text { (NCT01108094) }\end{array}$ & laBCC & - & - \\
\hline & & & $\begin{array}{l}\text { Phase 2: } 150 \mathrm{mg} \mathrm{2x/d} \mathrm{p.o.} \\
\qquad(\text { NCT02354261)* }\end{array}$ & BCSS & - & - \\
\hline & & $\begin{array}{l}\text { Taladegib } \\
\quad(\text { LY2940680) }\end{array}$ & Phase 1 (NCT01226485) & $\mathrm{laBCC} / \mathrm{mBCC}$ & - & - \\
\hline & & LEQ-506 & Phase 1 (NCT01106508) & $\mathrm{laBCC} / \mathrm{mBCC}$ & - & - \\
\hline & & BMS-833923 & Phase 1 (NCT00670189) & $\begin{array}{l}\mathrm{laBCC} / \mathrm{mBCC} / \\
\mathrm{BCCS}\end{array}$ & - & - \\
\hline & & TAK-441 & Phase 1 (NCT01204073) & laBCC & - & - \\
\hline & & $\begin{array}{l}\text { Patidegib } \\
\quad \text { (Saridegib, IPI- } \\
\text { 926) }\end{array}$ & Phase 1 (NCT01609179) & laBCC & - & - \\
\hline & & ZSP1602 & Phase 1 (NCT03734913) & laBCC & - & - \\
\hline & $\begin{array}{l}\text { Casein } \\
\text { kinase } 2 \\
\text { inhibitor }\end{array}$ & $\begin{array}{l}\text { Silmitasertib (CX- } \\
\text { 4945) }\end{array}$ & Phase 1 (NCT03897036)* & $\mathrm{laBCC} / \mathrm{mBCC}$ & - & - \\
\hline \multirow[t]{3}{*}{$\begin{array}{l}\text { Immune } \\
\text { checkpoint } \\
\text { inhibitors }\end{array}$} & \multirow{3}{*}{$\begin{array}{l}\text { PD1 } \\
\text { inhibitors/ } \\
\text { CTLA-4 } \\
\text { inhibitors }\end{array}$} & $\begin{array}{l}\text { Pembrolizumab } \\
\quad( \pm \text { Vismodegib })\end{array}$ & $\begin{array}{l}\text { Phase } 1-2: 200 \mathrm{mg} \mathrm{q} 3 \mathrm{w} \text { iv } \\
\quad( \pm 150 \mathrm{mg} 1 \mathrm{x} / \mathrm{d}) \\
(\text { NCT02690948) }\end{array}$ & $\mathrm{laBCC} / \mathrm{mBCC}$ & - & - \\
\hline & & $\begin{array}{l}\text { Nivolumab } \\
\quad( \pm \text { Ipilimumab })\end{array}$ & $\begin{array}{l}\text { Phase 2: } 480 \mathrm{mg} \mathrm{q} 4 \mathrm{w} \text { iv } \\
\quad( \pm 1 \mathrm{mg} / \mathrm{kg} \mathrm{q} 4 \mathrm{w} \text { for } 4 \\
\text { weeks iv) } \\
(\text { NCT03521830)* }\end{array}$ & $\mathrm{laBCC} / \mathrm{mBCC}$ & - & - \\
\hline & & Cemiplimab & $\begin{array}{l}\text { Phase 2: } 350 \mathrm{mg} \mathrm{q3w} \mathrm{iv} \\
(\text { NCT03132636)* }\end{array}$ & $\mathrm{laBCC} / \mathrm{mBCC}$ & - & - \\
\hline Intralesional & $\begin{array}{l}\text { Oncolytic } \\
\text { virus }\end{array}$ & $\begin{array}{l}\text { Talimogene- } \\
\text { Laherparepvec }\end{array}$ & $\begin{array}{l}\text { Phase 1: Max. } 4 \mathrm{ml} \\
10^{\wedge} 6-10^{\wedge} 8 \mathrm{PFU} / \mathrm{ml} \mathrm{q2w} \\
\text { intralesional } \\
(\text { NCT03458117)* }\end{array}$ & laBCC & - & - \\
\hline
\end{tabular}

SMO, Smoothened protein; PD1, programmed cell death protein 1; CTLA-4, cytotoxic T-lymphocyte-associated protein 4; p.o., per os; q2w, every 2 weeks; q3w, every 3 weeks; q4w, every 4 weeks; iv, intravenous; NCT, ClinicalTrials.gov registry number; PFU, plaque-forming units; laBCC, locally advanced basal-cell carcinoma; mBCC, metastatic basal-cell carcinoma; BCCS, basal-cell carcinoma syndrome. *Actively recruiting clinical trials as of April 2020 


\section{Immune Checkpoint Inhibition}

Because of UV-induced DNA damage, BCCs carry a high mutational burden [26], which usually leads to an abundance of tumor neoantigens. Therefore, BCCs are theoretically good candidates for an effective T-cell-mediated immunotherapy (e.g., immune checkpoint inhibition). As the therapeutic effects on other NMSC, namely cutaneous squamous cell carcinomas, are convincing, inhibitors of programed cell death protein 1 (PD1) such as pembrolizumab, nivolumab and cemiplimab have now entered clinical trials for laBCCs alone or in combination with SMO inhibitors. Encouraging pivotal data are available from case reports and a proof-of-concept study [27-31]. Of note, similar reports are available for ipilimumab, a cytotoxic T-lymphocyte-associated protein 4 (CTLA4) inhibitor [32]. Ipilimumab as a single agent is currently not under investigation for treatment of laBCC; however, a clinical trial includes ipilimumab in combination with nivolumab after progressive disease upon PD1 blockade (NCT03521830). Based on growing experience in the treatment of melanoma and other solid tumors, treatment modalities are now widely known among oncologists. Adverse events most often include immune-related cutaneous, gastrointestinal and hepatic inflammatory reactions as well as endocrine disruptions [33]. Severe and potentially lifethreatening side effects are possible, especially in combinatorial treatments. However, early detection via close follow-up and ideal therapeutic management diminish those risks. It is likely that these agents will broaden the armamentarium once efficacy has been proven.

\section{Intralesional Treatment}

In case of contraindications to the above-mentioned systemic therapies, locoregionary approaches may be a viable alternative to achieve tumor control. Electrochemotherapy is a technique that combines electroporation with administration of chemotherapeutic agents such as bleomycin or cisplatin to enhance efficacy and reduce systemic side effects. It may be helpful to control recurrent bleeding, pain or odor of the tumor. However, the procedure is painful, and availability is limited in most countries.

A phase I trial now explores the use of talimogene laherparepvec (T-VEC), which is approved for treatment of metastatic melanoma with limited involvement of skin and accessible lymph nodes (American Joint Committee on Cancer stage IIIB-IVA) in NMSC (NCT03458117). T-VEC is a modified herpes simplex virus that combines toxic effects on tumor cells with an immune-mediated anti-tumoral response (oncolytic virotherapy). The mechanism of action is virus-induced cytolysis combined with a pro-inflammatory release of granulocyte-macrophage colony-stimulating factor, which is integrated in the viral genome. The drug is directly injected into tumors or metastases; the dose is dependent on the extension of the lesions. Side effects are generally mild and include local reactions, pyrexia and fatigue.

\section{Chemotherapy}

Before the advent of targeted therapies and immunotherapies, laBCC not amenable or refractory to surgery and radiotherapy and patients with metastatic BCCs were treated with different chemotherapy regimens (e.g., cisplatin and paclitaxel, bleomycine) with varying degrees of success [34]. Treatment may be offered to eligible patients based on comorbidities and patient desire despite limited evidence. It is noteworthy that remissions lasted only months in most reports; other therapeutic options and inclusion in clinical studies should be preferred, if possible.

\section{Neoadjuvant Approach}

It should be mentioned that the above-listed treatment regimens may enable a curative excision in case of excellent partial remissions. Active neoadjuvant clinical trials are listed for vismodegib and sonidegib as of April 2020 (NCT03035188, NCT03534947). Promising results regarding lesion size reduction after a 3-month treatment scheme are available from a 
pivotal study [35]. Further studies are warranted to integrate this approach into standard care.

As our female patient is otherwise healthy apart from laBCCs on the scalp, we expect her to return to the clinic after regrowth of the BCCs. A rechallenge with SMO inhibitors would be one treatment option, as is inclusion in clinical studies or an off-label therapy with checkpoint inhibitors. However, all these therapies require sufficient patient adherence.

\section{CONCLUSION}

In summary, there are different treatment options for patients suffering from laBCCs, who remain a vulnerable group with a high burden of disease. Surgery remains the first-line treatment modality; an interdisciplinary approach is desirable to determine the best suitable pretherapeutic imaging and operative strategy. Radiotherapy must be considered for those patients unamenable to surgery. $\mathrm{HH}$ signaling inhibitors are the most important alternative. Clinical management should involve the patient's individual needs and wishes as well as consideration of prior treatments. Clinical trials deserve attention just like neoadjuvant approaches. The latter should be recognized as an attractive option to enable curative resections and to avoid continued high costs and side effects of medical treatments. Results of ongoing clinical trials exploring the use of immune checkpoint inhibitors are excitedly anticipated.

\section{ACKNOWLEDGEMENTS}

Funding. No funding or sponsorship was received for this study or publication of this article.

Authorship. All named authors meet the International Committee of Medical Journal Editors (ICMJE) criteria for authorship for this article, take responsibility for the integrity of the work as a whole, and have given their approval for this version to be published.
Author's Contributions. Dennis Niebel had the idea for the article, performed the literature search and data analysis. The first draft of the manuscript was written by Dennis Niebel and all authors commented on previous versions of the manuscript. All authors read and approved the final manuscript.

Disclosures. Dennis Niebel has received speaker's honoraria or travel expense reimbursements from the following companies: BMS, Novartis, GlaxoSmithKline (GSK), Celgene, Kiowa Kirin and Merck Sharp \& Dohme (MSD). Judith Sirokay has received speaker's honoraria from Novartis, BMS, MSD and Roche. Friederike Hoffmann has received speakers' honoraria or travel expense reimbursements from the following companies: Roche, BMS, Pierre Fabre, Novartis and MSD. Anne Fröhlich has received speaker's honoraria or travel expense reimbursements from the following companies: Novartis, BMS, Almirall, and Eli Lilly Pharma. Thomas Bieber and Jennifer Landsberg have nothing to disclose.

Compliance with Ethics Guidelines. The patient has consented to the submission of the case report to the journal and signed informed consent regarding publishing her data and photographs. We thank the patient for granting permission to publish this information and clinical pictures.

Data Availability. Data sharing is not applicable to this article as no datasets were generated or analyzed during the current study.

Prior Presentation. This information has previously been presented at the Dermatologie Kompakt und Praxisnah Conference 2020 in Dresden, Germany (7-9 February 2020).

Open Access. This article is licensed under a Creative Commons Attribution-NonCommercial 4.0 International License, which permits any non-commercial use, sharing, adaptation, distribution and reproduction in any medium or format, as long as you give appropriate credit to the original author(s) and the source, provide a link to the Creative Commons licence, and 
indicate if changes were made. The images or other third party material in this article are included in the article's Creative Commons licence, unless indicated otherwise in a credit line to the material. If material is not included in the article's Creative Commons licence and your intended use is not permitted by statutory regulation or exceeds the permitted use, you will need to obtain permission directly from the copyright holder. To view a copy of this licence, visit http://creativecommons.org/licenses/by$\mathrm{nc} / 4.0 /$.

\section{REFERENCES}

1. Rogers HW, Weinstock MA, Feldman SR, Coldiron $\mathrm{BM}$. Incidence estimate of nonmelanoma skin cancer (keratinocyte carcinomas) in the US population, 2012. JAMA Dermatol. 2015;151:1081-6.

2. Guy GP, Machlin SR, Ekwueme DU, Yabroff KR. Prevalence and costs of skin cancer treatment in the US, 2002-2006 and 2007-2011. Am J Prev Med. $2015 ; 48: 183-7$.

3. Mohan SV, Chang ALS. Advanced basal cell carcinoma: epidemiology and therapeutic innovations. Curr Dermatol Rep. 2014;3:40-5.

4. Lang BM, Balermpas P, Bauer A, Blum A, Brölsch GF, Dirschka T, et al. S2k guidelines for cutaneous basal cell carcinoma-part 1: epidemiology, genetics and diagnosis: S2k guidelines for basal cell carcinoma-part 1. JDDG J Dtsch Dermatol Ges. 2019;17:94-103.

5. Peris K, Fargnoli MC, Garbe C, Kaufmann R, Bastholt L, Seguin NB, et al. Diagnosis and treatment of basal cell carcinoma: European consensus-based interdisciplinary guidelines. Eur J Cancer. 2019;118: $10-34$.

6. Gorlin RJ, Goltz RW. Multiple nevoid Basal-cell epithelioma, jaw cysts and bifid rib. N Engl J Med. May 5;1960:908-12.

7. Love WE, Bernhard JD, Bordeaux JS. Topical imiquimod or fluorouracil therapy for basal and squamous cell carcinoma: a systematic review. Arch Dermatol. 2009;145:1431-8.

8. Bichakjian CK, Olencki T, Aasi SZ, Alam M, Andersen JS, Berg D, et al. Basal cell skin cancer, Version 1.2016, NCCN clinical practice guidelines in oncology. J Natl Compr Canc Netw. 2016;14: 574-97.
9. Lang BM, Balermpas P, Bauer A, Blum A, Brölsch GF, Dirschka T, et al. S2k guidelines for cutaneous basal cell carcinoma - part 2: treatment, prevention and follow-up: S2k Guidelines for Basal Cell Carcinoma - Part 2. JDDG J Dtsch Dermatol Ges. 2019;17:214-30.

10. Kakkassery V, Heindl LM. Standard operation procedure in periorbital basal cell carcinoma. Ophthalmol. 2020;117:124-124.

11. Rokohl AC, Kopecky A, Guo Y, Kakkassery V, Mor JM, Loreck N, et al. Surgical resection with ophtalmoplastic reconstruction: gold standard in periocular basal cell carcinoma. Ophthalmol. 2020;117: 95-105.

12. Avril MF, Auperin A, Margulis A, Gerbaulet A, Duvillard P, Benhamou E, et al. Basal cell carcinoma of the face: surgery or radiotherapy? Results of a randomized study. Br J Cancer. 1997;76:100-6.

13. Kwan W, Wilson D, Moravan V. Radiotherapy for locally advanced basal cell and squamous cell carcinomas of the skin. Int J Radiat Oncol. 2004;60: 406-11.

14. Baker S, Joseph K, Tai P. Radiotherapy in Gorlin syndrome: can it be safe and effective in adult patients? J Cutan Med Surg. 2016;20:159-62.

15. Carballo GB, Honorato JR, de Lopes GPF, Spohr TCL de SE. A highlight on Sonic Hedgehog pathway. Cell Commun Signal. 2018;16:11.

16. Sekulic A, Migden MR, Basset-Séguin N, Garbe C, Gieserich A, Lao CD, et al. Long-term safety and efficacy of vismodegib in patients with advanced basal cell carcinoma: final update of the pivotal ERIVANCE BCC study. BMC Cancer. 2017;17:332.

17. Basset-Séguin N, Hauschild A, Kunstfeld R, Grob J, Dréno B, Mortier L, et al. Vismodegib in patients with advanced basal cell carcinoma: primary analysis of STEVIE, an international, open-label trial. Eur J Cancer. 2017;86:334-48.

18. Dummer R, Guminksi A, Gutzmer R, Lear JT, Lewis $\mathrm{KD}$, Chang ALS, et al. Long-term efficacy and safety of sonidegib in patients with advanced basal cell carcinoma: 42-month analysis of the phase II randomized, double-blind BOLT study. Br J Dermatol. 2019; [Epub ahead of print].

19. Villani A, Fabbrocini G, Costa C, Scalvenzi M. Sonidegib: safety and efficacy in treatment of advanced basal cell carcinoma. Dermatol Ther. 2020; [Epub ahead of print].

20. Dréno B, Kunstfeld R, Hauschild A, Fosko S, Zloty D, Labeille B, et al. Two intermittent vismodegib dosing regimens in patients with multiple basal-cell 
carcinomas (MIKIE): a randomised, regimen-controlled, double-blind, phase 2 trial. Lancet Oncol. 2017;18:404-12.

21. Frampton JE, Basset-Séguin N. Vismodegib: a review in advanced basal cell carcinoma. Drugs. 2018;78: 1145-56.

22. Sohn GK, Kwon GP, Bailey-Healy I, Mirza A, Sarin $\mathrm{K}$, Oro A, et al. Topical itraconazole for the treatment of basal cell carcinoma in patients with basal cell nevus syndrome or high-frequency basal cell carcinomas: a phase 2, open-label, placebo-controlled trial. JAMA Dermatol. 2019; [Epud ahead of print].

23. Pounds R, Leonard S, Dawson C, Kehoe S. Repurposing itraconazole for the treatment of cancer. Oncol Lett. 2017;14:2587-97.

24. Migden MR. Targeted therapies in the treatment of advanced basal cell carcinoma. Clin Res Trials. $2018 ; 4$.

25. Epstein EH, Lear J, Saldanha G, Tang JY, Harwood C. Hedgehog pathway inhibition by topical patidegib to reduce BCC burden in patients with basal cell nevus (Gorlin) syndrome. J Clin Oncol. 2018;36:e21626-e2162621626.

26. Jayaraman SS, Rayhan DJ, Hazany S, Kolodney MS. Mutational landscape of basal cell carcinomas by whole-exome sequencing. J Invest Dermatol. 2014;134:213-20.

27. Ikeda S, Goodman AM, Cohen PR, Jensen TJ, Ellison CK, Frampton G, et al. Metastatic basal cell carcinoma with amplification of PD-L1: exceptional response to anti-PD1 therapy. Npj Genomic Med. 2016;1:16037.
28. Lipson EJ, Lilo MT, Ogurtsova A, Esandrio J, Xu H, Brothers $\mathrm{P}$, et al. Basal cell carcinoma: PD-L1/PD-1 checkpoint expression and tumor regression after PD-1 blockade. J Immunother Cancer. 2017;5:23.

29. Fischer S, Ali OH, Jochum W, Kluckert T, Flatz L, Siano M. Anti-PD-1 therapy leads to near-complete remission in a patient with metastatic basal cell carcinoma. Oncol Res Treat. 2018;41:391-4.

30. Cannon JGD, Russell JS, Kim J, Chang ALS. A case of metastatic basal cell carcinoma treated with continuous PD-1 inhibitor exposure even after subsequent initiation of radiotherapy and surgery. JAAD Case Rep. 2018;4:248-50.

31. Chang ALS, Tran DC, Cannon JGD, Li S, Jeng M, Patel R, et al. Pembrolizumab for advanced basal cell carcinoma: an investigator-initiated, proof-ofconcept study. J Am Acad Dermatol. 2019;80: 564-6.

32. Mohan SV, Kuo KY, Chang ALS. Incidental regression of an advanced basal cell carcinoma after ipilimumab exposure for metastatic melanoma. JAAD Case Rep. 2016;2:13-5.

33. Niebel D, Wenzel J. Immunopathology of cutaneous drug eruptions. Pathology. 2018;39:563-70.

34. Wysong A, Aasi SZ, Tang JY. Update on metastatic basal cell carcinoma: a summary of published cases from 1981 through 2011. JAMA Dermatol. 2013;149:615.

35. Ally MS, Aasi S, Wysong A, Teng C, Anderson E, Bailey-Healy I, et al. An investigator-initiated openlabel clinical trial of vismodegib as a neoadjuvant to surgery for high-risk basal cell carcinoma. J Am Acad Dermatol. 2014;71:904-11. 